\title{
Numerical simulation of two tool turning process
}

\author{
Kalidasan Rathinam ${ }^{1 *}$ and Sandeep $\operatorname{Kumar}^{2}$ \\ ${ }^{1}$ School of Mechanical Engineering, Lovely Professional University, Punjab, India \\ ${ }^{2}$ Department of Mechanical Engineering, Indian Institute of Technology Ropar, Punjab, India
}

\begin{abstract}
Double tool turning process is used to improve productivity. A 2D finite element model was developed using commercially available finite element analysis software Abaqus 6.13. The workpiece and the cutting tool materials are modelled as elasto-plastic and elastic material respectively. Johnson-Cook damage criterion was used for chip separation. The friction between the cutting tool and the workpiece is modelled based on penalty contact approach. The coefficient of friction between the chip and the first and second cutting tool was taken as 0.8 and 0.6 respectively. In this numerical investigation the effect tool separation distance over the cutting force, feed force and cutting temperature were studied. Three different tool separation distances were considered. The simulation result shows that cutting force and feed force of the front cutting tool and the rear cutting tool do not change appreciably with the variation of the tool separation distance. It was revealed that the temperature rise of the work material due to machining by two cutting tool is well below the recrystallization temperature. Hence the forces on front and rear cutting tool remain same for various tool separation distances. It was also observed that the cutting temperatures remained unchanged for the various tool separation distances.
\end{abstract}

\section{Introduction}

Numerical simulation of double tool turning process helps in increasing the productivity by conserving the resources. It also provides a detailed insight of the turning process. Many researchers had focused their attention on turning simulation, since it is a fundamental machining process. Baker [1] developed a generic two dimensional model using finite element method to study the influence of cutting speed on cutting force. It was revealed that the cutting force decreased when the cutting speed is increased. In addition the morphology of chip also changed from continuous to segmented chip. Dogu et al. [2] determined the temperature distribution in orthogonal cutting by a numerical model. The maximum cutting temperature was found for various cutting conditions. The simulation results agreed well with the literature. Duan et al. [3] simulated the chip formation process of AISI 1045 hardened steel. The influence of rake angle on cutting forces and chip morphology was studied. It was reported that finite element simulation could accurately determine the cutting force and chip features agreeing with the experimental results. Davim et al. [4] employed a Lagrangian FE model to predict the plastic strain distribution, cutting forces and cutting temperature. It was observed that the difference between simulated and experimental cutting force was $20 \%$ where us for cutting temperature it was $15 \%$. Akbar et al. [5] used a fully coupled thermo-mechanical FE model to study the fraction of heat passed into the cutting tool. Commercially available software Abaqus 6.6 was used. It was shown that the tool-chip interface temperature, tool-chip contact length and von Mises stresses depends on the heat partition between the chip and tool. The model was also validated through experiments. Ucun and Aslantas [6] carried out numerical simulation of AISI
4340 steel using single layer and multi-layer coated carbide tools. Johnson-Cook material model was used for elastic-plastic work deformation. The effect of coating on cutting forces, tool stresses and cutting temperatures was evaluated. It was observed that the shear angle was maximum for coated tool and minimum for uncoated tool. Calamaz et al. [7] analyzed shear localization process in titanium alloy. The influence of thermal and strain softening and cutting parameters on the cutting temperature was studied. It was noted that the coefficient of friction affected the tool-chip interface temperature and shear band frequency. $\mathrm{Hu}$ and Huang [8] performed computational analysis of AISI 4340 steel with a ceramic tool for various turning speeds. Deform 3D software was employed to compute the effects of cutting speed on tool wear, cutting forces and temperature. It was noted that the diffusion wear becomes dominant when the cutting speed is increased, and the cutting forces decreases due to the softening of work material caused by its temperature rise.

It is observed that lot of research on numerical simulation has been performed on traditional turning process. In case of two tool turning process, two cutting tools are simultaneous used to machine the workpiece resulting in higher productivity. Few analytical and experimental works on double tool turning are reported as follows.

Budak and Ozturk [9] analysed the dynamic stability while turning with two tools simultaneously. The use of two tools created a shock absorber effect, thereby increasing the stability of turning process. Ozturk et al. [10] formulated the stability of parallel turning process in frequency domain and time domain for two different conditions. It was observed that best process stability was achieved when the natural frequencies of the two tools are slightly different. Azvar and Budak [11] presented a multi-dimensional model to

\footnotetext{
* Corresponding author: kalidasan.22180@1pu.co.in
} 
analyse chatter stability during parallel double tool turning. The increase in nose radii and side cutting edge angle of the cutting tools increased the stability of turning process. Kalidasan et al. [12] investigated experimentally the effect of turning parameters on cutting forces and temperatures in double tool turning of cast iron and steel with a carbide tool. It was reported that, the separation distance between the two cutting tool did not have a significant effect on the cutting force component. Another experimental work of Kalidasan et al. [13] dealt about tool wear, chip morphology and machining accuracy. It was found that the front cutting tool exhibited predominant abrasive wear while the rear cutting tool showed both adhesive and diffusion wear.

It is observed from the literature that no computational work has been performed on double tool turning process even though it offers a lot of advantages such as savings in time and cost, increased tool life and improved surface finish, reduced cutting forces and temperature. The present work aims to fulfil that research gap. The primary objective of this research work is to develop a numerical model of double tool turning process and to determine the effect of tool separation distance on cutting force components and cutting temperature.

\section{Finite Element Model}

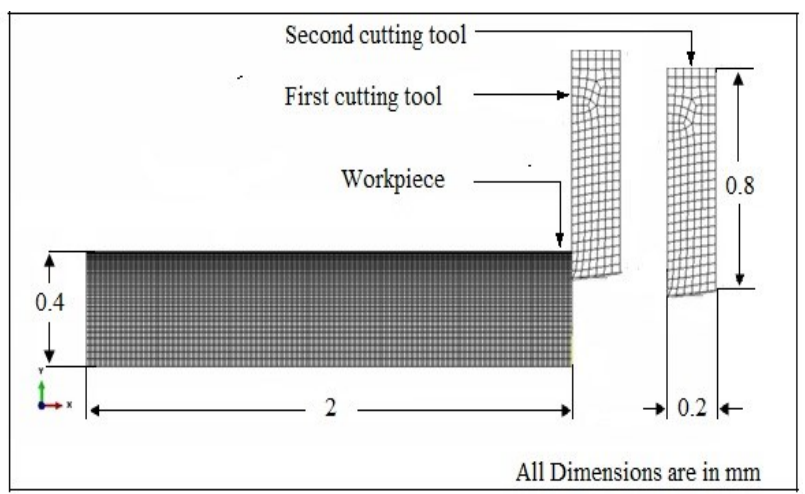

Fig. 1. Meshed FE model of double tool turning process

Fig. 1 shows the meshed finite element model of double tool turning process. The geometric model consists of two 2D deformable shell elements. The cutting tool is provided with neutral rake angle and with a clearance angle of $7^{\circ}$. The values are taken from the literature [5].

\subsection{Material model}

Johnson-Cook material model is considered for the AISI 4140 work material. This model is very widely used in machining process simulation because it takes into account the effect of strain, strain rate and temperature on the flow stress behavior of the material. The flow stress is given by
$\bar{\sigma}=\left(A+B \bar{\varepsilon}^{n}\right)\left[1+C \ln \left(\frac{\dot{\bar{\varepsilon}}}{\dot{\bar{\varepsilon}}}\right)\right]\left[1-\left(\frac{\theta-\theta_{\text {room }}}{\theta_{\text {melting }}-\theta_{\text {room }}}\right)^{m}\right]$

where $A$ is the initial yield stress, $B$ is the hardening modulus, $C$ is the strain rate dependency coefficient, $\mathrm{n}$ is the work hardening coefficient, $\mathrm{m}$ is the thermal softening, is the plastic strain rate, $\bar{\varepsilon}$ is the equivalent plastic strain and in the reference strain rate, $\theta_{\text {melting }}$ is the melting temperature of the workpiece, $\theta$ is the process temperature $\theta_{\text {room }}$ is the ambient temperature. An equivalent plastic strain criterion is adopted to formulate the chip formation. Material failure depends upon the critical value of equivalent plastic strain. This cumulative law is stated as

$$
D=\sum\left(\frac{\Delta \bar{\varepsilon}}{\bar{\varepsilon}_{f}}\right)
$$

where $D$ is the damage parameter, $\bar{\varepsilon}_{f}$ is the equivalent strain at failure $\Delta \bar{\varepsilon}$ is the increment of equivalent plastic strain. Equivalent plastic strain is given by

$\bar{\varepsilon}_{f}=\left[D_{1}+D_{2} \exp \left(D_{3} \frac{P}{\bar{\sigma}}\right)\right]\left[1+D_{4} \ln \left(\frac{\dot{\bar{\varepsilon}}}{\dot{\bar{\varepsilon}}_{0}}\right)\right]\left[1+D_{5}\left(\frac{\theta-\theta_{\text {room }}}{\theta_{\text {melt }}-\theta_{\text {room }}}\right)\right]$

where $P$ is the hydrostatic pressure. $D_{1}, D_{2}, D_{3}, D_{4}$ and $D_{5}$ are the experimentally obtained failure constants. Numerical model of Pantale et al. [14] provides the Johnson-Cook and damage parameters as shown in Table 1. The thermo-mechanical properties of work material and cutting tool are referred from the work of Akbar et al. [5]. Material stiffness start degrading after element satisfies the damage initiation criterion. Failure is assumed to occur when $D$ value exceeds 1 . After the element is fully degraded, element deletion equal to yes is specified in Abaqus software to completely remove the element.

Table 1. Johnson-Cook parameters of AISI 4140

\begin{tabular}{|c|c|c|c|c|}
\hline $\boldsymbol{A}(\mathbf{M P a})$ & $\boldsymbol{B}(\mathbf{M P a})$ & $\mathbf{n}$ & $\boldsymbol{C}$ & $\mathbf{m}$ \\
\hline 595 & 580 & 0.133 & 0.023 & 1.03 \\
\hline $\boldsymbol{D}_{1}$ & $\boldsymbol{D}_{2}$ & $\boldsymbol{D}_{3}$ & $\boldsymbol{D}_{4}$ & $\boldsymbol{D}_{5}$ \\
\hline 1.5 & 3.44 & -2.12 & 0.002 & 0.1 \\
\hline
\end{tabular}

\subsection{Explicit dynamic analysis}

Formulation based on explicit dynamic analysis is generally used for highly non-linear problems like machining which involves large amount of deformations. Explicit dynamic is an integration technique which uses the central difference method to move the solution further in time. Explicit analysis uses the information already it has for obtaining the unknown information. It does not require any iteration or convergence check for obtaining the solution. It is designed to study the highly non-linear, discontinuous and high speed dynamic problems. It requires lesser disk space as compare to standard analysis. In this simulation work temperature displacement coupled explicit dynamic analysis is used. 


\subsection{Contact model}

A kinematic contact algorithm has been used to establish the contact between the tool rake surface and the chip. Penalty contact with a constant coefficient of friction is used to model the contact between the chip and cutting tool. The experimental work of Kalidasan et al. [12] revealed the coefficient of friction between the chip and the first and second cutting tool as 0.8 and 0.6 respectively. Frictional forces are taken into consideration with the help of tangential behavior effect.

\subsection{Meshing and Boundary condition}

CPE4RT four node plane strain bilinear displacement and temperature quadrilateral elements are used. Additionally reduced integration scheme and hourglass control are used for both the cutting tool and workpiece. Workpiece consist of 10010 elements and 10332 nodes while the tool consists of 168 elements and 200 nodes. In coupled temperature displacement elements stress analysis is coupled with the heat transfer. The selected elements have both temperature and displacement degree of freedom. Elements can use linear or parabolic interpolation for displacement but can use only the linear interpolation for the temperature in coupled temperature displacement type element. Machining generates a lot of heat which affects the mechanical properties of the work piece hence coupled analysis is preferred. Workpiece is kept fixed. All the degrees of freedom at the base of workpiece are arrested to prevent displacement. Workpiece dimension are kept such that it will attain a steady state condition while machining. Cutting tools are given velocity in the negative $\mathrm{X}$ direction and it is constrained in the $\mathrm{Y}$ direction. In this work, a cutting velocity of $395 \mathrm{~m} / \mathrm{min}$ and depth of cut of $0.1 \mathrm{~mm}$ is taken with $0.4,0.8$ and $1.2 \mathrm{~mm}$ as separation distances between the cutting tools.

\section{Numerical results and discussion}

The distance between the two cutting tools is an additional cutting parameter in double tool turning process. Therefore numerical simulation was performed to evaluate the effect of the tool separation distance on the cutting force and cutting temperature. It is to be noted that first and second cutting tool are referred as front and rear cutting tool.

\subsection{Effect of tool separation distance on cutting force components}

The cutting forces generated by two cutting tools during the numerical simulation process are shown in Fig. 2.

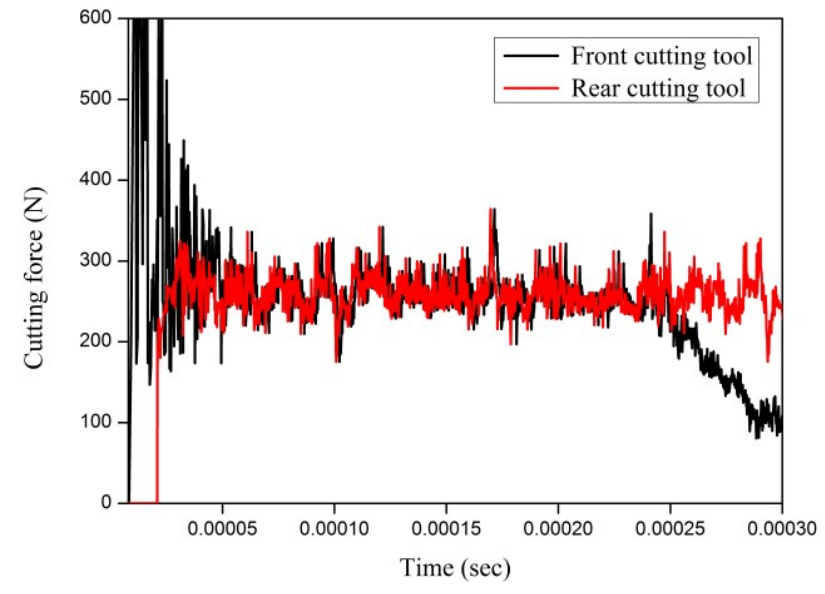

Fig. 2. Simulated cutting forces of front and rear cutting tool

The cutting conditions are already mentioned in section 2.4. It was observed that a transient region existed for about 0.05 milliseconds for the front cutting tool and thereafter a steady cutting force of $260 \mathrm{~N}$ was generated. On contrary for the rear cutting tool the transient region is almost non-existence as it is machining the already machined surface. It is to be noted that the mean cutting force of the rear cutting tool was $265 \mathrm{~N}$. Thus the difference between the main cutting forces of front and rear cutting tool is less than $2 \%$. Hence it can be said the front and rear cutting generated same magnitude of cutting force for similar cutting conditions. On similar lines the feed force generated by the front and rear tools are $108 \mathrm{~N}$ and $96 \mathrm{~N}$. This accounts for $42 \%$ and $36 \%$ of the cutting forces of front and rear cutting tool respectively. The lesser value of feed forces of the rear cutting tool is due to lower coefficient of friction. Chisholm [15] reported that in orthogonal cutting the friction coefficient value lies in the range of 0.5 to 1 . For the present simulation the friction coefficient values are mentioned in section 2.3. Lower friction coefficient of 0.6 between the rear cutting tool and chip may be attributed to reduced feed force, compared with front cutting tool.

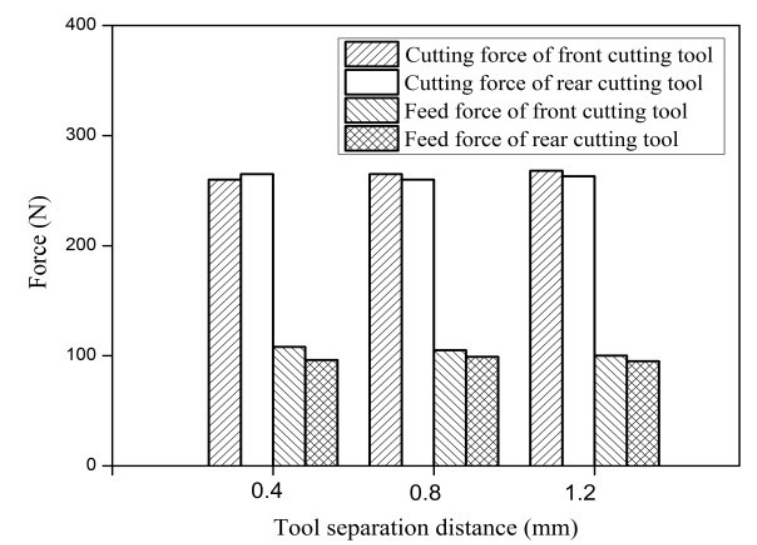

Fig. 3. Effect of tool separation distance on cutting force and feed force of front cutting tool and rear cutting tool 
Fig. 3 shows the influence of tool separation distance on cutting and feed forces of both the cutting tools. It can be seen that when the tool separation distance is increased from $0.4 \mathrm{~mm}$ to $0.8 \mathrm{~mm}$ the variation in cutting force and feed force of front cutting tools are 2\% and 3\% respectively. For the rear tool it is $3 \%$ for both forces. Again on increasing from $0.8 \mathrm{~mm}$ to $1.2 \mathrm{~mm}$ the change in cutting force and feed force of front and rear cutting tools is $1 \%, 5 \%, 1 \%$ and $4 \%$ respectively. Thus it is evident that the cutting and feed forces of both the cutting tools does not vary appreciably on changing the tool separation distance.

\subsection{Effect of tool separation distance on cutting temperature}

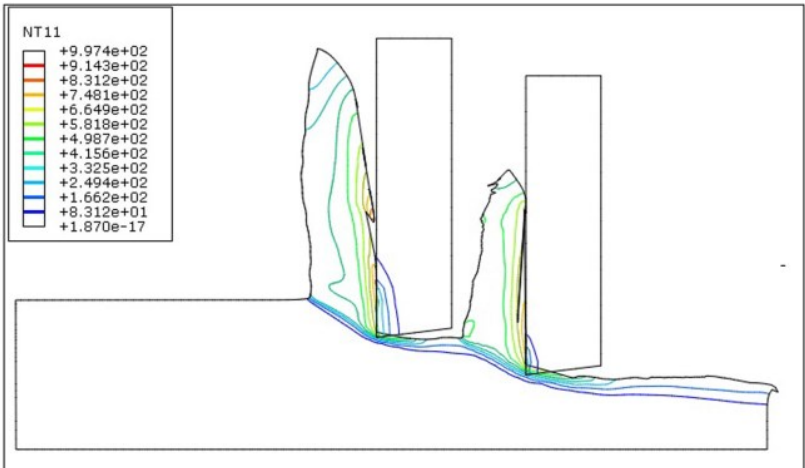

Fig. 4. Cutting temperature distribution for $0.4 \mathrm{~mm}$ tool separation distance

Fig. 4 shows the cutting temperature distribution on the chip, cutting tool and workpiece for a cutting velocity of $395 \mathrm{~m} / \mathrm{min}, 0.1 \mathrm{~mm}$ depth of cut with $0.4 \mathrm{~mm}$ as distance between the two tools. The maximum cutting temperature at secondary deformation zone was $914^{\circ} \mathrm{C}$ where us at the tertiary deformation zone the temperature was $83^{\circ} \mathrm{C}$. The bulk mean temperature of the workpiece is well below the recrystallization temperature of the work material. Kalidasan et al.[16] experimentally measured the cutting temperature while turning gray cast iron with two carbide cutting tools. It was reported that the bulk mean temperature of $56^{\circ} \mathrm{C}$ was attained by the work material for certain cutting condition. For the tool separation distance of $0.8 \mathrm{~mm}$ and $1.2 \mathrm{~mm}$ the maximum cutting temperatures are $908^{\circ} \mathrm{C}$ and $912^{\circ} \mathrm{C}$. On the other hand the work material temperature remained $83^{\circ} \mathrm{C}$ under all cutting conditions. The work material properties remain unaltered as the workpiece is below its recrystallization temperatures in all the three tool separation distances. Hence it can be said that the cutting temperatures remains constant immaterial of the tool separation distances.

\section{Conclusions}

FE model was developed and numerical simulation was performed for the double tool turning process. Following conclusions are arrived based on the numerical simulation process.
- The cutting and feed forces generated by the front and rear cutting remain almost same for the simulated cutting conditions. The average cutting force and feed force are $264 \mathrm{~N}$ and 101 $\mathrm{N}$ with variation less than $7 \%$.

- The magnitude of cutting and feed force is not influenced by tool separation distances. Therefore cutting and feed forces remained constant immaterial of tool separation distance for the selected cutting conditions.

- The maximum cutting temperature reached was above $900^{\circ} \mathrm{C}$ but the bulk mean temperature of the workpiece was $83^{\circ} \mathrm{C}$. The bulk work material temperature is well below its recrystallization temperature. Variation of tool separation distance did not cause any change in the mean temperature of the work material.

\section{References}

1. M. Baker, J. Mater. Process. Technol., 176, 117-126 (2006)

2. Y. Dogu, E. Aslan, N. Camuscu, J. Mater. Process. Technol., 171, 1-9 (2006)

3. C.Z. Duan, T. Dou, Y.J. Cai, Int. J. Recent trends Eng., 1(5), 46-50 (2009)

4. J. Paulo Davim, C. Maranhão, P. Faria, A. Abrão, J. C. Rubio, Leonardo R. Silva, Int J Adv Manuf Technol., 42, 842-849 (2009)

5. F. Akbar, P.T. Mativenga, M.A. Sheikh, Int J Adv Manuf Technol., 46, 491-507 (2010)

6. I. Ucun, K. Aslantas, Int J Adv Manuf Technol., 54, 899-910 (2011)

7. M. Calamaz, D. Coupard, M. Nouari, F. Girot, Int J Adv Manuf Technol., 52, 887-895 (2011)

8. H. Hu, W. Huang, Int J Adv Manuf Technol., 67 (14), 907-915 (2013)

9. E. Budak, E. Ozturk, CIRP Ann Manuf Technol., 60, 383-386 (2011)

10. E. Ozturk, A. Comak, E. Budak, J. Sound Vibration, 360, 17-30 (2016)

11. M. Azvar, E. Budak, Int J Mach Tools Manuf, 123, 116-128 (2017)

12. R. Kalidasan, M. Yatin, D.K. Sarma, S. Senthilvelan, U.S. Dixit. IJMMM, 18 (5/6), 540-551 (2016)

13. R. Kalidasan, S. Senthilvelan, U.S. Dixit, J. Vaibhav, Int. J. Precision Technology, 6(2), 142157 (2016)

14. O. Pantale, J.L. Bacaria, O. Dalverny, R. Rakotomalala, S. Caperaa, Comput. Methods Appl. Mech. Engrg., 193, 4383-4399 (2004)

15. A.J. Chisholm, Proc. Mech Eng., 165, 14-21 (1951)

16. R. Kalidasan, M. Yatin, D.K. Sarma, S. Senthilvelan, Appl Mech Mater., 592-594, 211-215 (2014) 